\title{
The Treg/Th17 Axis: A Dynamic Balance Regulated by the Gut Microbiome
}

\author{
Sara Omenetti and Theresa T. Pizarro* \\ Department of Pathology, Case Western Reserve University School of Medicine, Cleveland, OH, USA
}

T-helper 17 (Th17) and T-regulatory (Treg) cells are frequently found at barrier surfaces, particularly within the intestinal mucosa, where they function to protect the host from pathogenic microorganisms and to restrain excessive effector T-cell responses, respectively. Despite their differing functional properties, Th17 cells and Tregs share similar developmental requirements. In fact, the fate of antigen-naïve T-cells to either Th17 or Treg lineages is finely regulated by key mediators, including TGF $\beta$, IL-6, and all-trans retinoic acid. Importantly, the intestinal microbiome also provides immunostimulatory

\section{OPEN ACCESS}

Edited by:

Amélia M. Sarmento,

Universidade Fernando Pessoa,

Portugal

Reviewed by:

Masaaki Murakami,

Hokkaido University, Japan

Tobias Bopp,

University Medical Center Mainz,

Germany

Anne L. Astier

University of Edinburgh, UK

*Correspondence:

Theresa T. Pizarro

theresa.pizarro@case.edu

Specialty section:

This article was submitted to Mucosal Immunity,

a section of the journal

Frontiers in Immunology

Received: 10 September 2015 Accepted: 04 December 2015

Published: 17 December 2015

Citation:

Omenetti S and Pizarro TT (2015)

The Treg/Th17 Axis: A Dynamic

Balance Regulated by the Gut

Microbiome.

Front. Immunol. 6:639.

doi: 10.3389/fimmu.2015.00639 signals, which can activate innate and downstream adaptive immune responses. Specific components of the gut microbiome have been implicated in the production of proinflammatory cytokines by innate immune cells, such as IL-6, IL-23, IL-1 $\beta$, and the subsequent generation and expansion of Th17 cells. Similarly, commensal bacteria and their metabolites can also promote the generation of intestinal Tregs that can actively induce mucosal tolerance. As such, dysbiosis of the gut microbiome may not solely represent a consequence of gut inflammation, but rather shape the Treg/Th17 commitment and influence susceptibility to inflammatory bowel disease. In this review, we discuss Treg and Th17 cell plasticity, its dynamic regulation by the microbiome, and highlight its impact on intestinal homeostasis and disease.

Keywords: T-regulatory cells, T-helper 17 cells, intestinal homeostasis, gut microbiome, inflammatory bowel disease

\section{INTRODUCTION}

The gastrointestinal tract represents the largest surface area of the human body that comes into direct contact with the external environment. Consequently, the gut mucosa is exposed to a massive amount and diverse range of foreign antigens. Host detection of pathogenic microbes by antigenpresenting cells (APCs) results in cytokine production, as well as recruitment and differentiation of T-helper (Th) cells. The nature of the offending organisms is crucial for the differentiation into

\footnotetext{
Abbreviations: AhR, aryl hydrocarbon receptor; AMPK, adenosine monophosphate-activated kinase; APC, antigen-presenting cell; ATP, adenosine triphosphate; BFT, Bacteroides fragilis toxin; DC, dendritic cell; GF, germ-free; GPR, G-protein receptor; HIF1 $\alpha$, hypoxia-inducible factor $1 \alpha$; IBD, inflammatory bowel disease; IL-23R, IL-23 receptor; Ig, immunoglobulin; iTreg, induced Treg; LP, lamina propria; mTOR, mammalian target of rapamycin; nTreg, natural Treg; PSA, polysaccharide A; RA, retinoic acid; SCFA, short-chain fatty acid; SFB, segmented filamentous bacteria; SI, small intestine; TCR, T-cell receptor; Th, T-helper; Treg, T-regulatory cell; Trl, T-regulatory type I cell.
} 
Th cells, and once contained, effector responses are counterbalanced by Tregs that limit collateral damage. In peripheral organs, such as the gut, the balance between Treg/effector cells is normally achieved by in situ induction of these cells from naïve T-cells, recruitment of differentiated Treg/effector cells into the tissue, and reprogramming of already differentiated Treg/effector cells towards other lineages in peripheral tissues $(1,2)$.

\section{Treg/Th17 AXIS IN HEALTH AND DISEASE}

\section{Treg and Th17 Cells: Similarities Beyond Functional Opposites}

Th17 cells have only recently been identified as a unique $\mathrm{CD} 4^{+}$ T-helper subset, characterized by IL-17 production that promotes tissue inflammation $(3,4)$. Understanding their function during homeostatic and inflammatory conditions is continuously evolving; however, it is increasingly clear that Th17 cells are critical in protecting mucosal surfaces against microbial pathogens, including bacteria, fungi, and viruses $(5,6)$, particularly in the lamina propria (LP) of the small intestine (SI), where they are abundantly present (7). Notoriety of Th17 cells initially emerged with the report that IL-17-producing T-cells, driven by IL-23, were major contributors to autoimmune inflammation (8). Indeed, the initial discovery that IL-23, rather than IL-12, was required to develop disease in experimental models of inflammation $(9,10)$ led to the reevaluation of T-cells that drive IL-23-dependent inflammation.

Over the last two decades, Tregs have been identified as dedicated suppressors of diverse immune responses and inflammation, and central keepers of peripheral tolerance. Tregs are generated in both the thymus (natural Tregs and nTregs) and the periphery (iTregs). While iTregs resemble nTregs in phenotype and function, there are also differences, most prominently regarding their epigenetic and transcriptional status, as well as their inherent stability (11-13). Indeed, when naïve $\mathrm{CD}^{+} \mathrm{T}$-cells recognize antigen presented as self, in the absence of any inflammatory stimuli, tolerance is induced and these cells, at least partially, differentiate into Tregs. Accordingly, organs exposed to a wide repertoire of foreign antigens, such as the gut, may be dominated by Tregs arising from peripheral conversion, rather than thymiccell differentiation. The peripheral antigenic landscape may also affect selective expansion of Treg T-cell receptor (TCR) clonotype (14) that is presumably dependent on a peripheral antigenic niche (15). According to this scenario, iTregs represent an essential, non-redundant regulatory subset that supplements nTregs, in part by expanding TCR diversity (16).

Although Tregs and Th17 cells fundamentally differ in function, they also display many common features. Both populations are abundantly found in the periphery, particularly in the intestine $(7,17)$, and are composed of heterogeneous subpopulations that are able to change effector or suppressor capabilities under different conditions (2). Moreover, shared mechanisms and key mediators (e.g., lineage-specific transcription factors, cytokines) regulate Th17 cells and Tregs, similar to other T-helper subsets. The pleiotropic cytokine, TGF $\beta$, for example, is essential for differentiation of both cell types. TGF $\beta$ is non-redundantly required for the generation of Tregs (18) but dispensable for the development of Th17 cells (19). IL-1 $\beta$ can substitute TGF $\beta$ in IL-6-mediated generation of Th17 cells (20). Thus, in the absence of proinflammatory signals, such as IL-6 produced by microbial-activated dendritic cells (DCs) or IL-21 produced by IL-6-stimulated T-cells (21-23), priming of naïve $\mathrm{CD} 4^{+} \mathrm{T}$-cells by antigen in an environment rich in TGF $\beta$ promotes the development of iTregs $(24,25)$. Conversely, activation in an environment wherein both TGF $\beta$ and IL- 6 are available promotes Th17 development, at least at mucosal sites (26).

Nonetheless, it is perplexing how the same cytokine can regulate differentiation of T-cells with opposing functions. The answer likely lies in TGF $\beta$ 's concentration-dependent function. At low concentrations, TGF $\beta$ synergizes with IL- 6 and IL-21 to promote IL-23 receptor (IL-23R) expression, favoring Th17 differentiation (21-23), whereas at high concentrations, TGF $\beta$ represses IL-23R and favors Foxp $3^{+}$Tregs, which in turn inhibits ROR $\gamma$ t function (27). Conversely, IL-21 and IL-23 can relieve Foxp3-mediated inhibition of ROR $\gamma \mathrm{t}$, thereby promoting Th17 differentiation (27). Therefore, the decision of antigen-stimulated cells to differentiate into either Th17 or Tregs depends upon the cytokine-regulated balance of the two master regulators of these cells, ROR $\gamma \mathrm{t}$ and Foxp3, respectively. Several other mediators can also influence the balance between Th17 and Tregs. RA, a metabolite of vitamin A, preferentially induces Tregs over Th17 cells by enhancing TGF $\beta$ signaling while blocking IL-6R expression (28). Moreover, aryl hydrocarbon receptor (AhR), highly expressed on Th17 and Tregs, can promote the induction of both cell types by integrating environmental stimuli $(29,30)$. Environmental stimuli affecting gastrointestinal immunity via AhR can consist of both dietaryand bacteria-produced ligands, which can interact directly with AhR $(31,32)$. Interestingly, the loss of bacteria-producing AhR ligands may influence gut immunity and increase the risk of colitis (33).

\section{Treg/Th17 Plasticity}

Several studies have established that differentiation of Foxp $3^{+}$ Tregs is not static and that Tregs can differentiate into Th17 cells. This phenomenon was first reported in mice, wherein IL-6 was shown to convert Foxp $3^{+}$cells to Th17 cells in the absence of TGF $\beta$ (34-36), which was confirmed in humans $(37,38)$. In contrast to "Th1-like" Tregs, IL-17-secreting Tregs are suppressive in vitro but lose this capacity upon stimulation with IL-1 $\beta$ and IL-6 (38). Accordingly, among ROR $\gamma \mathrm{t}^{+} \mathrm{T} \alpha \beta$ cells derived from different murine tissues, the presence of Foxp $3^{+}$cells that function as Tregs has been reported that coexist with IL-17-producing ROR $\gamma \mathrm{t}^{+} \mathrm{T} \alpha \beta$ cells (39). In this study, the ratio of Foxp $3^{+}$to IL-17-producing ROR $\gamma \mathrm{t}^{+} \mathrm{T} \alpha \beta$ cells is skewed in favor of IL-10 production by Foxp3 and CCL20 and in favor of IL-17 by IL- 6 and IL-23. It is unclear why only some IL-17+ cells express Foxp3, and how this is biological relevant. It is possible that Foxp3 activation occurs during Th17 programming, or alternatively, that Foxp3 expression may signify a distinct differentiation pathway. A recent report showed that under arthritic conditions, CD $25^{\text {lo }}$ Foxp $3^{+} \mathrm{CD} 4^{+}$T-cells lose Foxp3 expression and undergo IL-6-dependent transdifferentiation into Th17 cells, which accumulate in inflamed joints. Once 
adoptively transferred into mice, these cells are able to accelerate the onset, and increase severity, of arthritis and associate with loss of Foxp3 expression in the majority of transferred T-cells (40). Interestingly, IL-17-producing Foxp $3^{+} \mathrm{CD}^{+}$ lymphocytes are also observed in inflammatory bowel disease (IBD) patients (41). These cells share phenotypic characteristics with both Th17 and Tregs and show potent in vitro suppressor activity (42) and increased sensitivity to Th17-generating cytokines in IBD patients versus controls (41). Although Tregs are not sufficient at controlling inflammation in IBD, it is unclear whether or not they retain their suppressive function. Increasing, albeit confounding, evidence points to the different cell origins responsible for this discrepancy $(43,44)$, adding further complexity to the biological relevance of the functional and phenotypic overlap between Treg and Th17 cells observed in $\operatorname{IBD}(41,42)$.

Whether Th17 cells represent a terminally differentiated lineage or a metastable state is still an area of debate. Multiple studies have identified a Th17 subset that coproduces IFN $\gamma$, such as in the inflamed intestine, where they display developmental plasticity $(45,46)$. Generally, Th17 cells can retain an IL-17 $\mathrm{A}^{+}$phenotype, or lose IL-17 and acquire expression of IFN $\gamma$, in a process driven by IL-12 and IL-23 via a STAT4- and T-bet-dependent manner (47), thus giving rise to Th1-like cells. The latter Th17 subset does not possess colitogenic potential, whereas the former, derived from a Th17 precursor, can mediate experimental colitis via STAT- 4 and T-bet, but not through IL-2 or IFN $\gamma$ receptors (48). One reason that Th17 cells display considerable developmental plasticity may be that ROR $\gamma$ t does not participate in stabilizing positive feedback toward transcription factor activation, thus rendering its expression sensitive to environmental signals (49).

Until recently, the conversion between Treg and Th17 was thought to be a one-way street, wherein Tregs can unidirectionally convert into Th17 cells (34). Although coexpression of Th17 and Treg signature genes has been reported in the same cells $(38,39)$, it is unclear whether Th17 cells can undergo a global reprogramming that drives conversion to another Th-type or that they simply display phenotypic plasticity. Gagliani et al. made the seminal discovery that under homeostatic conditions, intestinal Th17 cells can lose IL-17 expression and a fraction of these "exTh17" cells acquire regulatory features resembling CD $4^{+}$Foxp $3^{-}$Type 1 Tregs ( $\operatorname{Tr} 1)$ (50). This conversion is determined by reprogramming of the Th17-relevant transcriptional profile, referred to as "transdifferentiation" $(51,52)$. The functional reprogramming experienced by exTh17 into $\operatorname{Tr} 1$ is irreversible; indeed, these cells display anti-inflammatory properties by preventing Th17mediated colitis (50). While Th17 cells generated with TGF $\beta 1 /$ IL-6/IL-23 are able to promote colitis, exTh17 Tr1 cells generated under the same conditions fail to induce disease. In fact, although TGF $\beta 1$ is important for exTh17 Tr1 cell development, Th17 cells remain colitogenic, despite the presence of TGF $\beta 1$, as long as they do not convert into $\operatorname{Tr} 1$ cells (50). While the main cytokines orchestrating Treg/Th17 plasticity have been identified (Figure 1), the fine balance of environmental stimuli required for directing T-helper cells toward one lineage versus another is still known.

\section{REGULATION OF THE Treg/Th17 AXIS BY THE GUT MICROBIOME}

\section{Metabolic Control of Th17 and Tregs}

Environmental signals and microbiome sensors can profoundly affect $\mathrm{T}$-cell differentiation and response to immune stimuli. Generally, activated effector T-cells are anabolic, primarily employing glucose as their carbon source and utilizing glycolysis for fast access to adenosine triphosphate (ATP). Memory and resting $\mathrm{T}$-cells are instead catabolic with the ability to metabolize fatty and amino acids, in addition to glucose, and depend on oxidative phosphorylation to generate ATP (53). Two key mediators of the glycolytic and lipogenic pathways in T-cells are mammalian target of rapamycin (mTOR) and adenosine monophosphateactivated kinase (AMPK), which promote de novo fatty acid synthesis and fatty acid oxidation, consequently inducing either energy production or storage, respectively (54). Both mTOR and AMPK act as crucial cellular energy sensors and are regulated by the availability of nutrients $(55,56)$. Th17 cells depend on acetyl-CoA carboxylase 1-mediated de novo fatty acid synthesis and the underlying glycolytic-lipogenic metabolic pathway for their development, whereas Tregs rely on oxidative phosphorylation and consume their required fatty acids exogenously (57). Upregulation of the glycolic pathway in Th17 cells can also be activated by the transcription factor, hypoxia-inducible factor $1 \alpha(\mathrm{HIF} 1 \alpha)(58)$ that binds to the locus encoding ROR $\gamma \mathrm{t}$ and enhances its expression while inhibiting Foxp3. Together, this promotes T-cell differentiation toward Th17 and prevents Treg commitment under both normoxic and hypoxic conditions (59). Differently from Foxp $3^{+}$Tregs, Tr1 metabolism is supported by glycolysis via HIF $1 \alpha$ in early metabolic reprogramming and by AhR at later stages, which then promotes HIF $1 \alpha$ degradation (60). Both hypoxia and extracellular ATP increased at inflammatory sites $(61,62)$, triggered AhR inactivation, and inhibited $\operatorname{Tr} 1$ differentiation (60). Therefore, metabolic factors present in the microenvironment have immune-modifying potential, which can skew the balance between inflammation and immune tolerance by biasing the decision of T-cell fate toward either Th17 or Treg lineages.

\section{Regulation of Th17 and Treg by the Commensal Flora}

The importance of the gut microbiome in regulating the Treg/ Th17 axis became widely appreciated when different groups reported that germ-free (GF) mice demonstrate a decreased frequency of SI Th17 cells and colonic Tregs $(63,64)$. One of the most widely investigated commensal bacteria in the context of Th17 immunity is segmented filamentous bacteria (SFB), a Clostridia-related species (65) that displays features between an obligate and facultative symbiont (66), suggesting that these bacteria obtain nutritional requirements from their host (65). Interest peaked when SFB was reported to specifically induce Th17 cells in the SI $(67,68)$ and in extraintestinal sites during autoimmune inflammation $(69,70)$. SFB antigen is presented to CD4 ${ }^{+}$T-cells by DCs in a major histocompatibility complex-dependent manner, which is required for the induction of SFB-specific intestinal 




FIGURE 1 | Cytokine milieu orchestrates Treg and Th17 cell plasticity. Th17 cells lose stability in the absence of TGF $\beta$ and presence of IL-12, IL-23, and IL-1 $\beta$, favoring IFN $\gamma$ expression and differentiation into Th1/Th17 cells that produce both Th1 (e.g., IFN $\gamma$ ) and Th17 (e.g., IL-17, IL-22) cytokines. Further augmentation of IL-12 can fully convert Th1/Th17 cells into Th1 cells, whereas this process can be reverted by either TGF $\beta$ and IL-6 or in the absence of retinoic acid (RA) in favor of Th1/Th17 or Th17 cells, respectively. Alternatively, the abundance of TGF $\beta$ in the absence of IL- 6 drives Th17 cells toward regulatory phenotypes, such as either ROR $\mathrm{t}^{+}$Foxp3+ Treg/Th17 cells or Foxp3- Tr1 cells. If proinflammatory cytokines are present, including either IL-6 or IL-1 $\beta$ and IL-6, Foxp3 ${ }^{+}$Tregs have the ability to transdifferentiate into either Th17 or Treg/Th17 cells, respectively.

Th17 cells $(71,72)$. SFB colonization of GF mice activates a wide range of antimicrobial defenses, including immunoglobulin (Ig) A secretion and LP production of antimicrobial peptides and proinflammatory cytokines $(63,67,68)$. SFB colonization is potentially beneficial since it attenuates bacteria-induced colitis (68), but it can also induce colitis in genetically susceptible mice (73), suggesting that while SFB can normally enhance immune control of infection, its presence can also result in inflammation. The abundance of SFB, together with gut barrier function, is regulated by the IL-23R/IL-22 pathway (74). When the intestinal barrier is disrupted, systemic dissemination of microbial products occurs, which invokes the IL-23 pathway and initiates barrier repair, as well as Th17 responses aimed to neutralize invading commensal microbes (74). Moreover, SFB-induced-IL-23 results in production of IL-22 by type 3 innate lymphoid cells, which is critical for the production of serum amyloid A proteins 1 and 2 by epithelial cells (75). This circuit promotes IL-17 expression in ROR $\gamma \mathrm{t}^{+} \mathrm{T}$ cells, especially in the terminal ileum, which is the site of SFB attachment to the epithelium, the essential condition for Th17 induction by SFB $(75,76)$. SFB-induced activation may also result in the generation of autoreactive Th17 cells in response to presentation of autoantigen in the setting of a breached intestinal barrier. SFB-mediated induction of Th17 immune responses can also occur indirectly via other cell types. Indeed, Treg-specific MyD88 deficiency is sufficient to impair intestinal IgA responses to SFB and results in the expansion of Th17 cells (77).

Another resident of the human gut microbiome influencing T-cell homeostasis is the symbiont, Bacteroides fragilis. Bacteroides species are normal constituents of the intestinal microbiome; however, under certain circumstances, these microbes can become pathogens. Polysaccharide A (PSA), the most abundant capsular polysaccharide expressed by $B$. fragilis, mediates conversion of $\mathrm{CD}^{+}$T-cells into IL-10-producing Foxp $3^{+}$Tregs via TLR2 and suppresses Th17 responses, thus facilitating colonization of $B$. fragilis (78). Consistently, PSA is able to both prevent and ameliorate experimental colitis (79), suggesting that $B$. fragilis facilitates Treg differentiation in the gut and induces mucosal tolerance. Nevertheless, strains of $B$. fragilis secreting the zinc metalloprotease, $B$. fragilis toxin (BFT), have been implicated in $\operatorname{IBD}(80,81)$ and in IL-17-dependent inflammation-associated colon cancer (82). Indeed, BFT can alter the function of intestinal epithelial tight junctions, resulting in increased permeability and diarrhea (83).

Other bacterial strains, such as Clostridia, are able to induce Tregs within the gut. Most Clostridia maintain a commensal relationship with the host, with a few exceptions, including Clostridia perfringens, Clostridia difficile, and Clostridia tetani, which produce toxins and are pathogenic. Colonization of GF mice with a defined mixture of 46 Clostridium strains belonging to clusters XIVa and IV induces the differentiation of colonic Helios-negative Tregs in a MyD88-independent manner (64). Additionally, a mixture of 17 strains from Clostridiales clusters VI, XIVa, and XVIII isolated from human feces also exhibits Treginducing activity (84) and suggests that Clostridium-dependent induction of Tregs may contribute to the maintenance of intestinal immune homeostasis. Similarly, colonization of GF mice with altered Schaedler flora, a standardized cocktail of benign intestinal commensal microbiota, results in the de novo generation of Tregs and downregulation of Th1 and Th17 immunity (85). A summary of bacterial strains influencing Treg and Th17 intestinal immune responses are depicted in Figure 2.

The precise mechanism(s) underlying colonic Treg induction by the gut microbiome remains unclear, although several reports suggest that commensal, microbe-derived short-chain fatty acids 




FIGURE 2 | Impact of the gut microbiota on Treg and Th17 immune responses. Colonization with segmented filamentous bacteria (SFB) occurs by intimate attachment to the intestinal epithelium and promotes the development of Th17 cells via intestinal epithelial cell (IEC)-derived cytokines, serum amyloid A (SAA), as well as antigen presentation by dendritic cells (DCs). Adhesion of SFB to IEC can potentially generate a circuit, wherein DC-derived IL-23 stimulates IL-22 production by type 3 innate lymphoid cells (ILC3), which in turn induces SAA from IEC and can lead to Th17 cell differentiation. Conversely, colonization of beneficial commensal bacteria induces de novo generation of Tregs and downregulates Th17 immune responses. Commensal bacteria, including most Clostridia species, produce short-chain fatty acids, i.e., butyrate, which participates in the de novo generation of Tregs by suppressing proinflammatory cytokines, by promoting RA production from DCs, and by inducing Foxp3 transcription. Among different Bacteroides fragilis strains, those expressing polysaccharide A (PSA) mediate the generation of Tregs via TLR2, while those secreting B. fragilis toxin (BFT) alter the function of IEC tight junctions. Upon disruption of barrier function, dissemination of microbial products, recognized by microbe-associated molecular patterns (MAMPs), occurs and activates the IL-23 pathway, resulting in subsequent barrier repair and stimulation of Th17 immune responses.

(SCFAs), particularly those from Clostridiales, may be involved (86-88). SCFAs, together with organic acids and alcohols, are metabolic end products generated in the lower gastrointestinal tract from fermentative growth of carbohydrates and proteins that cannot be degraded (89). Specifically, locally produced butyrate participates in colonic de novo Treg development, whereas oral administration of acetate and propionate contributes to Treg migration into the colon by upregulating G-protein receptor (GPR)15 (90). Indeed, in vivo administration of butyrate suppresses proinflammatory cytokines from macrophages and DCs, likely through inhibition of histone deacetylases $(87,91)$, and ameliorates experimental colitis (88). Butyrate participates in Treg differentiation by facilitating histone $\mathrm{H} 3$ acetylation in the promoter and conserved non-coding sequence regions 1 and 3 of the Foxp3-encoding locus (88) or by activating its receptor, GPR109a, that promotes RA production in DCs and leads to induction of Treg differentiation (92). Interestingly, T-cell regulation by SCFAs is dependent on the cytokine milieu and immunological context. Indeed, acetate promotes IL-10-producing T-cells during steady-state conditions and effector Th1 and Th17 cells during active immune responses (93). Other dietary-related factors, such as fat-enriched diets, have been implicated in gut microbial regulation of intestinal immunity. In fact, high-fatdiet-derived microbiota decreases Th17 cell frequency and the ability of intestinal APCs to generate Th17 cells in vitro, thus contributing to low-grade inflammation (94).

\section{Dysbiosis Affecting the Th17/Treg Axis in IBD}

Dysbiosis is considered an alteration of the resident commensal microenvironment compared to commensal communities found 
in healthy individuals and has been reported in many diseases, including IBD (95). Dysbiosis can be classified into three different, non-mutually exclusive, categories: loss of beneficial microbial organisms, expansion of pathobionts, and loss of overall microbial diversity (96). Interestingly, reduced abundance of butyrate-producing bacteria, i.e., Clostridiales cluster IV and XIVa, has been found in IBD patient fecal samples (95), supporting the hypothesis that presence of beneficial bacteria inducing Treg differentiation is important to prevent IBD. Although there is no single organism capable of inducing IBD, a few pathogens have been implicated. Two colitogenic proteobacteria, Proteus mirabilis and Klebsiella pneumonia, have been identified in ulcerative colitis-like $\mathrm{T}$-bet ${ }^{-/}-\mathrm{Rag} 2^{-/-}$mice that spontaneously develop dysbiosis and colitis $(97,98)$. However, maternally transmitted endogenous microbes are also required to maximize inflammation in these mice (98), suggesting that microbe interaction may determine whether a pathobiont will display a pathogenic profile. Similarly, IBD patients display an increased number of Actinobacteria and Proteobacteria (95). Intestinal T-cell homeostasis appears to be dependent not only on the type of bacteria present but also on overall microbial diversity. Indeed, the transfer of over 30 different human Clostridia strains into GF mice induced a threefold expansion of Tregs compared to uncolonized controls, whereas transfer of a single strain from the same

\section{REFERENCES}

1. Littman DR, Rudensky AY. Th17 and regulatory $\mathrm{T}$ cells in mediating and restraining inflammation. Cell (2010) 140:845-58. doi:10.1016/j. cell.2010.02.021

2. Brucklacher-Waldert V, Carr EJ, Linterman MA, Veldhoen M. Cellular plasticity of CD4+ T cells in the intestine. Front Immunol (2014) 5:488. doi:10.3389/fimmu.2014.00488

3. Harrington LE, Hatton RD, Mangan PR, Turner H, Murphy TL, Murphy KM, et al. Interleukin 17-producing CD4+ effector T cells develop via a lineage distinct from the T helper type 1 and 2 lineages. Nat Immunol (2005) 6:1123-32. doi:10.1038/ni1254

4. Park H, Li Z, Yang XO, Chang SH, Nurieva R, Wang YH, et al. A distinct lineage of $\mathrm{CD} 4 \mathrm{~T}$ cells regulates tissue inflammation by producing interleukin 17. Nat Immunol (2005) 6:1133-41. doi:10.1038/ni1261

5. Khader SA, Gaffen SL, Kolls JK. Th17 cells at the crossroads of innate and adaptive immunity against infectious diseases at the mucosa. Mucosal Immunol (2009) 2:403-11. doi:10.1038/mi.2009.100

6. Curtis MM, Way SS. Interleukin-17 in host defence against bacterial, mycobacterial and fungal pathogens. Immunology (2009) 126:177-85. doi:10.1111/j.1365-2567.2008.03017.x

7. Ivanov II, McKenzie BS, Zhou L, Tadokoro CE, Lepelley A, Lafaille JJ, et al. The orphan nuclear receptor RORgammat directs the differentiation program of proinflammatory IL-17+ T helper cells. Cell (2006) 126:1121-33. doi:10.1016/j.cell.2006.07.035

8. Langrish CL, Chen Y, Blumenschein WM, Mattson J, Basham B, Sedgwick JD, et al. IL-23 drives a pathogenic T cell population that induces autoimmune inflammation. J Exp Med (2005) 201:233-40. doi:10.1084/jem.20041257

9. Gran B, Zhang GX, Yu S, Li J, Chen XH, Ventura ES, et al. IL-12p35-deficient mice are susceptible to experimental autoimmune encephalomyelitis: evidence for redundancy in the IL-12 system in the induction of central nervous system autoimmune demyelination. J Immunol (2002) 169:7104-10. doi:10.4049/ jimmunol.169.12.7104

10. Zhang GX, Gran B, Yu S, Li J, Siglienti I, Chen X, et al. Induction of experimental autoimmune encephalomyelitis in IL-12 receptor-beta 2-deficient mice: IL-12 responsiveness is not required in the pathogenesis of inflammatory demyelination in the central nervous system. J Immunol (2003) 170:2153-60. doi:10.4049/jimmunol.170.4.2153
Clostridia collection induced a more modest Treg response (64, 84 ), suggesting that greater microbial diversity maximizes host immune responses and its reduction may contribute to inflammatory processes, such as in IBD (99).

\section{CONCLUSION}

Although progress has been made in clarifying the role of the microbiome in Treg and Th17 mucosal immunity, its impact on disease, such as IBD, remains controversial. A better understanding of the mechanisms regulating these processes may aid in the development of therapeutic agents aimed to maintain appropriate Treg/Th17 balance and restore homeostatic function during disease states.

\section{AUTHOR CONTRIBUTIONS}

SO and TP conceptualized review. SO provided an initial draft of the review, while TP performed the final edits.

\section{FUNDING}

This work was supported by grants from the National Institutes of Health: DK056762, DK091222, and AI102269 (to TP).

11. Baron U, Floess S, Wieczorek G, Baumann K, Grutzkau A, Dong J, et al. DNA demethylation in the human FOXP3 locus discriminates regulatory $\mathrm{T}$ cells from activated FOXP3(+) conventional T cells. Eur J Immunol (2007) 37:2378-89. doi:10.1002/eji.200737594

12. Ohkura N, Kitagawa Y, Sakaguchi S. Development and maintenance of regulatory $\mathrm{T}$ cells. Immunity (2013) 38:414-23. doi:10.1016/j. immuni.2013.03.002

13. Hill JA, Feuerer M, Tash K, Haxhinasto S, Perez J, Melamed R, et al. Foxp3 transcription-factor-dependent and -independent regulation of the regulatory T cell transcriptional signature. Immunity (2007) 27:786-800. doi:10.1016/j. immuni.2007.09.010

14. Lathrop SK, Santacruz NA, Pham D, Luo J, Hsieh CS. Antigen-specific peripheral shaping of the natural regulatory T cell population. J Exp Med (2008) 205:3105-17. doi:10.1084/jem.20081359

15. Nishio J, Feuerer M, Wong J, Mathis D, Benoist C. Anti-CD3 therapy permits regulatory $\mathrm{T}$ cells to surmount $\mathrm{T}$ cell receptor-specified peripheral niche constraints. J Exp Med (2010) 207:1879-89. doi:10.1084/jem.20100205

16. Haribhai D, Williams JB, Jia S, Nickerson D, Schmitt EG, Edwards B, et al. A requisite role for induced regulatory $\mathrm{T}$ cells in tolerance based on expanding antigen receptor diversity. Immunity (2011) 35:109-22. doi:10.1016/j. immuni.2011.03.029

17. Maynard CL, Harrington LE, Janowski KM, Oliver JR, Zindl CL, Rudensky AY, et al. Regulatory T cells expressing interleukin 10 develop from Foxp3+ and Foxp3- precursor cells in the absence of interleukin 10. Nat Immunol (2007) 8:931-41. doi:10.1038/ni1504

18. Nakamura K, Kitani A, Strober W. Cell contact-dependent immunosuppression by CD4(+)CD25(+) regulatory T cells is mediated by cell surface-bound transforming growth factor beta. J Exp Med (2001) 194:629-44. doi:10.1084/ jem.194.5.629

19. Das J, Ren G, Zhang L, Roberts AI, Zhao X, Bothwell AL, et al. Transforming growth factor beta is dispensable for the molecular orchestration of Th17 cell differentiation. J Exp Med (2009) 206:2407-16. doi:10.1084/jem.20082286

20. Ghoreschi K, Laurence A, Yang XP, Tato CM, McGeachy MJ, Konkel JE, et al. Generation of pathogenic $\mathrm{T}(\mathrm{H}) 17$ cells in the absence of TGF-beta signalling. Nature (2010) 467:967-71. doi:10.1038/nature09447

21. Korn T, Bettelli E, Gao W, Awasthi A, Jager A, Strom TB, et al. IL-21 initiates an alternative pathway to induce proinflammatory T(H)17 cells. Nature (2007) 448:484-7. doi:10.1038/nature05970 
22. Nurieva R, Yang XO, Martinez G, Zhang Y, Panopoulos AD, Ma L, et al. Essential autocrine regulation by IL-21 in the generation of inflammatory $\mathrm{T}$ cells. Nature (2007) 448:480-3. doi:10.1038/nature05969

23. Zhou L, Ivanov II, Spolski R, Min R, Shenderov K, Egawa T, et al. IL-6 programs $\mathrm{T}(\mathrm{H})-17$ cell differentiation by promoting sequential engagement of the IL-21 and IL-23 pathways. Nat Immunol (2007) 8:967-74. doi:10.1038/ni1488

24. Bettelli E, Carrier Y, Gao W, Korn T, Strom TB, Oukka M, et al. Reciprocal developmental pathways for the generation of pathogenic effector TH17 and regulatory T cells. Nature (2006) 441:235-8. doi:10.1038/nature04753

25. Chen W, Jin W, Hardegen N, Lei KJ, Li L, Marinos N, et al. Conversion of peripheral CD4+CD25- naive $\mathrm{T}$ cells to CD4+CD25+ regulatory $\mathrm{T}$ cells by TGF-beta induction of transcription factor Foxp3. J Exp Med (2003) 198:1875-86. doi:10.1084/jem.20030152

26. Hu W, Troutman TD, Edukulla R, Pasare C. Priming microenvironments dictate cytokine requirements for T helper 17 cell lineage commitment. Immunity (2011) 35:1010-22. doi:10.1016/j.immuni.2011.10.013

27. Zhou L, Lopes JE, Chong MM, Ivanov II, Min R, Victora GD, et al. TGFbeta-induced Foxp3 inhibits $\mathrm{T}(\mathrm{H}) 17$ cell differentiation by antagonizing RORgammat function. Nature (2008) 453:236-40. doi:10.1038/nature06878

28. Mucida D, Park Y, Kim G, Turovskaya O, Scott I, Kronenberg M, et al. Reciprocal TH17 and regulatory T cell differentiation mediated by retinoic acid. Science (2007) 317:256-60. doi:10.1126/science.1145697

29. Veldhoen M, Hirota K, Westendorf AM, Buer J, Dumoutier L, Renauld JC, et al. The aryl hydrocarbon receptor links TH17-cell-mediated autoimmunity to environmental toxins. Nature (2008) 453:106-9. doi:10.1038/nature06881

30. Quintana FJ, Basso AS, Iglesias AH, Korn T, Farez MF, Bettelli E, et al. Control of $\mathrm{T}(\mathrm{reg})$ and $\mathrm{T}(\mathrm{H}) 17$ cell differentiation by the aryl hydrocarbon receptor. Nature (2008) 453:65-71. doi:10.1038/nature06880

31. Kiss EA, Vonarbourg C, Kopfmann S, Hobeika E, Finke D, Esser C, et al. Natural aryl hydrocarbon receptor ligands control organogenesis of intestinal lymphoid follicles. Science (2011) 334:1561-5. doi:10.1126/science.1214914

32. Lee JS, Cella M, McDonald KG, Garlanda C, Kennedy GD, Nukaya M, et al. the development of gut ILC22 cells and postnatal lymphoid tissues via pathways dependent on and independent of Notch. Nat Immunol (2012) 13:144-51. doi:10.1038/ni.2187

33. Li Y, Innocentin S, Withers DR, Roberts NA, Gallagher AR, Grigorieva EF, et al. Exogenous stimuli maintain intraepithelial lymphocytes via aryl hydrocarbon receptor activation. Cell (2011) 147:629-40. doi:10.1016/j.cell.2011.09.025

34. Xu L, Kitani A, Fuss I, Strober W. Cutting edge: regulatory T cells induce CD4+CD25-Foxp3- T cells or are self-induced to become Th17 cells in the absence of exogenous TGF-beta. J Immunol (2007) 178:6725-9. doi:10.4049/ jimmunol.178.11.6725

35. Osorio F, LeibundGut-Landmann S, Lochner M, Lahl K, Sparwasser T, Eberl G, et al. DC activated via dectin-1 convert Treg into IL-17 producers. Eur J Immunol (2008) 38:3274-81. doi:10.1002/eji.200838950

36. Yang XO, Nurieva R, Martinez GJ, Kang HS, Chung Y, Pappu BP, et al. Molecular antagonism and plasticity of regulatory and inflammatory $\mathrm{T}$ cell programs. Immunity (2008) 29:44-56. doi:10.1016/j.immuni.2008.05.007

37. Koenen HJ, Smeets RL, Vink PM, van Rijssen E, Boots AM, Joosten I. Human CD25highFoxp3pos regulatory $\mathrm{T}$ cells differentiate into IL-17-producing cells. Blood (2008) 112:2340-52. doi:10.1182/blood-2008-01-133967

38. Beriou G, Costantino CM, Ashley CW, Yang L, Kuchroo VK, Baecher-Allan C, et al. IL-17-producing human peripheral regulatory $\mathrm{T}$ cells retain suppressive function. Blood (2009) 113:4240-9. doi:10.1182/blood-2008-10-183251

39. Lochner M, Peduto L, Cherrier M, Sawa S, Langa F, Varona R, et al. In vivo equilibrium of proinflammatory IL-17+ and regulatory IL-10+ Foxp3+ RORgamma t+ T cells. J Exp Med (2008) 205:1381-93. doi:10.1084/ jem.20080034

40. Komatsu N, Okamoto K, Sawa S, Nakashima T, Oh-hora M, Kodama T, et al. Pathogenic conversion of Foxp3+ T cells into TH17 cells in autoimmune arthritis. Nat Med (2014) 20:62-8. doi:10.1038/nm.3432

41. Ueno A, Jijon H, Chan R, Ford K, Hirota C, Kaplan GG, et al. Increased prevalence of circulating novel IL-17 secreting Foxp3 expressing CD4+ T cells and defective suppressive function of circulating Foxp3+ regulatory cells support plasticity between Th17 and regulatory T cells in inflammatory bowel disease patients. Inflamm Bowel Dis (2013) 19:2522-34. doi:10.1097/ MIB.0b013e3182a85709
42. Hovhannisyan Z, Treatman J, Littman DR, Mayer L. Characterization of interleukin-17-producing regulatory $\mathrm{T}$ cells in inflamed intestinal mucosa from patients with inflammatory bowel diseases. Gastroenterology (2011) 140:957-65. doi:10.1053/j.gastro.2010.12.002

43. Yu QT, Saruta M, Avanesyan A, Fleshner PR, Banham AH, Papadakis KA. Expression and functional characterization of FOXP3+ CD4+ regulatory $\mathrm{T}$ cells in ulcerative colitis. Inflamm Bowel Dis (2007) 13:191-9. doi:10.1002/ ibd.20053

44. Makita S, Kanai T, Oshima S, Uraushihara K, Totsuka T, Sawada T, et al. CD4+CD25bright $\mathrm{T}$ cells in human intestinal lamina propria as regulatory cells. J Immunol (2004) 173:3119-30. doi:10.4049/jimmunol.173.5.3119

45. Annunziato F, Cosmi L, Santarlasci V, Maggi L, Liotta F, Mazzinghi B, et al. Phenotypic and functional features of human Th17 cells. J Exp Med (2007) 204:1849-61. doi:10.1084/jem.20070663

46. Acosta-Rodriguez EV, Rivino L, Geginat J, Jarrossay D, Gattorno M, Lanzavecchia A, et al. Surface phenotype and antigenic specificity of human interleukin 17-producing T helper memory cells. Nat Immunol (2007) 8:639-46. doi:10.1038/ni1467

47. Lee YK, Turner H, Maynard CL, Oliver JR, Chen D, Elson CO, et al. Late developmental plasticity in the T helper 17 lineage. Immunity (2009) 30:92-107. doi:10.1016/j.immuni.2008.11.005

48. Harbour SN, Maynard CL, Zindl CL, Schoeb TR, Weaver CT. Th17 cells give rise to Th1 cells that are required for the pathogenesis of colitis. Proc Natl Acad Sci U S A (2015) 112:7061-6. doi:10.1073/pnas.1415675112

49. Ciofani M, Madar A, Galan C, Sellars M, Mace K, Pauli F, et al. A validated regulatory network for Th17 cell specification. Cell (2012) 151:289-303. doi:10.1016/j.cell.2012.09.016

50. Gagliani N, Vesely MCA, Iseppon A, Brockmann L, Xu H, Palm NW, et al. TH17 cells transdifferentiate into regulatory $\mathrm{T}$ cells during resolution of inflammation. Nature (2015) 523:221-U225. doi:10.1038/nature14452

51. Graf T, Enver T. Forcing cells to change lineages. Nature (2009) 462:587-94. doi:10.1038/nature08533

52. Komatsu N, Mariotti-Ferrandiz ME, Wang Y, Malissen B, Waldmann H, Hori S. Heterogeneity of natural Foxp3(+) T cells: a committed regulatory T-cell lineage and an uncommitted minor population retaining plasticity. Proc Natl Acad Sci U S A (2009) 106:1903-8. doi:10.1073/pnas.0811556106

53. MacIver NJ, Michalek RD, Rathmell JC. Metabolic regulation of $\mathrm{T}$ lymphocytes. Annu Rev Immunol (2013) 31:259-83. doi:10.1146/ annurev-immunol-032712-095956

54. Michalek RD, Gerriets VA, Jacobs SR, Macintyre AN, MacIver NJ, Mason EF, et al. Cutting edge: distinct glycolytic and lipid oxidative metabolic programs are essential for effector and regulatory CD4(+) T cell subsets. J Immunol (2011) 186:3299-303. doi:10.4049/jimmunol.1003613

55. Chapman NM, Chi H. mTOR links environmental signals to T cell fate decisions. Front Immunol (2015) 5:686. doi:10.3389/fimmu.2014.00686

56. Hardie DG. AMPK: positive and negative regulation, and its role in wholebody energy homeostasis. Curr Opin Cell Biol (2015) 33:1-7. doi:10.1016/j. ceb.2014.09.004

57. Berod L, Friedrich C, Nandan A, Freitag J, Hagemann S, Harmrolfs K, et al. De novo fatty acid synthesis controls the fate between regulatory $\mathrm{T}$ and $\mathrm{T}$ helper 17 cells. Nat Med (2014) 20:1327-33. doi:10.1038/nm.3704

58. Shi LZ, Wang R, Huang G, Vogel P, Neale G, Green DR, et al. HIFlalphadependent glycolytic pathway orchestrates a metabolic checkpoint for the differentiation of TH17 and Treg cells. J Exp Med (2011) 208:1367-76. doi:10.1084/jem.20110278

59. Dang EV, Barbi J, Yang HY, Jinasena D, Yu H, Zheng Y, et al. Control of $\mathrm{T}(\mathrm{H}) 17 / \mathrm{T}(\mathrm{reg})$ balance by hypoxia-inducible factor 1. Cell (2011) 146:772-84. doi:10.1016/j.cell.2011.07.033

60. Mascanfroni ID, Takenaka MC, Yeste A, Patel B, Wu Y, Kenison JE, et al. Metabolic control of type 1 regulatory $\mathrm{T}$ cell differentiation by AHR and HIF1-alpha. Nat Med (2015) 21:638-46. doi:10.1038/nm.3868

61. Eltzschig HK, Carmeliet P. Hypoxia and inflammation. N Engl J Med (2011) 364:656-65. doi:10.1056/NEJMra0910283

62. Junger WG. Immune cell regulation by autocrine purinergic signalling. Nat Rev Immunol (2011) 11:201-12. doi:10.1038/nri2938

63. Ivanov II, Frutos Rde L, Manel N, Yoshinaga K, Rifkin DB, Sartor RB, et al. Specific microbiota direct the differentiation of IL-17-producing T-helper 
cells in the mucosa of the small intestine. Cell Host Microbe (2008) 4:337-49. doi:10.1016/j.chom.2008.09.009

64. Atarashi K, Tanoue T, Shima T, Imaoka A, Kuwahara T, Momose Y, et al. Induction of colonic regulatory $\mathrm{T}$ cells by indigenous Clostridium species. Science (2011) 331:337-41. doi:10.1126/science.1198469

65. Sczesnak A, Segata N, Qin X, Gevers D, Petrosino JF, Huttenhower C, et al. The genome of th17 cell-inducing segmented filamentous bacteria reveals extensive auxotrophy and adaptations to the intestinal environment. Cell Host Microbe (2011) 10:260-72. doi:10.1016/j.chom.2011.08.005

66. Klaasen HL, Koopman JP, Poelma FG, Beynen AC. Intestinal, segmented, filamentous bacteria. FEMS Microbiol Rev (1992) 8:165-80. doi:10.111 1/j.1574-6968.1992.tb04986.x

67. Ivanov II, Atarashi K, Manel N, Brodie EL, Shima T, Karaoz U, et al. Induction of intestinal Th17 cells by segmented filamentous bacteria. Cell (2009) 139:485-98. doi:10.1016/j.cell.2009.09.033

68. Gaboriau-Routhiau V, Rakotobe S, Lecuyer E, Mulder I, Lan A, Bridonneau $\mathrm{C}$, et al. The key role of segmented filamentous bacteria in the coordinated maturation of gut helper T cell responses. Immunity (2009) 31:677-89. doi:10.1016/j.immuni.2009.08.020

69. Lee YK, Menezes JS, Umesaki Y, Mazmanian SK. Proinflammatory T-cell responses to gut microbiota promote experimental autoimmune encephalomyelitis. Proc Natl Acad Sci U S A (2011) 108(Suppl 1):4615-22. doi:10.1073/ pnas. 1000082107

70. Wu HJ, Ivanov II, Darce J, Hattori K, Shima T, Umesaki Y, et al. Gut-residing segmented filamentous bacteria drive autoimmune arthritis via T helper 17 cells. Immunity (2010) 32:815-27. doi:10.1016/j.immuni.2010.06.001

71. Goto Y, Panea C, Nakato G, Cebula A, Lee C, Diez MG, et al. Segmented filamentous bacteria antigens presented by intestinal dendritic cells drive mucosal Th17 cell differentiation. Immunity (2014) 40:594-607. doi:10.1016/j. immuni.2014.03.005

72. Lecuyer E, Rakotobe S, Lengline-Garnier H, Lebreton C, Picard M, Juste C, et al. Segmented filamentous bacterium uses secondary and tertiary lymphoid tissues to induce gut IgA and specific T helper 17 cell responses. Immunity (2014) 40:608-20. doi:10.1016/j.immuni.2014.03.009

73. Stepankova R, Powrie F, Kofronova O, Kozakova H, Hudcovic T, Hrncir T, et al. Segmented filamentous bacteria in a defined bacterial cocktail induce intestinal inflammation in SCID mice reconstituted with CD45RBhigh CD4+ T cells. Inflamm Bowel Dis (2007) 13:1202-11. doi:10.1002/ibd.20221

74. Shih VF, Cox J, Kljavin NM, Dengler HS, Reichelt M, Kumar P, et al. Homeostatic IL-23 receptor signaling limits Th17 response through IL-22mediated containment of commensal microbiota. Proc Natl Acad Sci U S A (2014) 111:13942-7. doi:10.1073/pnas.1323852111

75. Sano T, Huang W, Hall JA, Yang Y, Chen A, Gavzy SJ, et al. An IL-23R/IL-22 circuit regulates epithelial serum amyloid A to promote local effector Th17 responses. Cell (2015) 163:381-93. doi:10.1016/j.cell.2015.08.061

76. Atarashi K, Tanoue T, Ando M, Kamada N, Nagano Y, Narushima S, et al. Th17 cell induction by adhesion of microbes to intestinal epithelial cells. Cell (2015) 163:367-80. doi:10.1016/j.cell.2015.08.058

77. Wang S, Charbonnier LM, Noval Rivas M, Georgiev P, Li N, Gerber G, et al. MyD88 adaptor-dependent microbial sensing by regulatory $\mathrm{T}$ cells promotes mucosal tolerance and enforces commensalism. Immunity (2015) 43(2):289-303. doi:10.1016/j.immuni.2015.06.014

78. Round JL, Lee SM, Li J, Tran G, Jabri B, Chatila TA, et al. The toll-like receptor 2 pathway establishes colonization by a commensal of the human microbiota. Science (2011) 332:974-7. doi:10.1126/science.1206095

79. Round JL, Mazmanian SK. Inducible Foxp3+ regulatory T-cell development by a commensal bacterium of the intestinal microbiota. Proc Natl Acad Sci U S A (2010) 107:12204-9. doi:10.1073/pnas.0909122107

80. Rabizadeh S, Rhee KJ, Wu S, Huso D, Gan CM, Golub JE, et al. Enterotoxigenic Bacteroides fragilis: a potential instigator of colitis. Inflamm Bowel Dis (2007) 13:1475-83. doi:10.1002/ibd.20265

81. Rhee KJ, Wu S, Wu X, Huso DL, Karim B, Franco AA, et al. Induction of persistent colitis by a human commensal, enterotoxigenic Bacteroides fragilis, in wild-type C57BL/6 mice. Infect Immun (2009) 77:1708-18. doi:10.1128/ IAI.00814-08

82. Wu S, Rhee KJ, Albesiano E, Rabizadeh S, Wu X, Yen HR, et al. A human colonic commensal promotes colon tumorigenesis via activation of $\mathrm{T}$ helper type 17 T cell responses. Nat Med (2009) 15:1016-22. doi:10.1038/nm.2015
83. Wu S, Lim KC, Huang J, Saidi RF, Sears CL. Bacteroides fragilis enterotoxin cleaves the zonula adherens protein, E-cadherin. Proc Natl Acad Sci U S A (1998) 95:14979-84. doi:10.1073/pnas.95.25.14979

84. Atarashi K, Tanoue T, Oshima K, Suda W, Nagano Y, Nishikawa H, et al. Treg induction by a rationally selected mixture of clostridia strains from the human microbiota. Nature (2013) 500:232-6. doi:10.1038/nature12331

85. Geuking MB, Cahenzli J, Lawson MA, Ng DC, Slack E, Hapfelmeier S, et al. Intestinal bacterial colonization induces mutualistic regulatory $\mathrm{T}$ cell responses. Immunity (2011) 34:794-806. doi:10.1016/j.immuni.2011.03.021

86. Smith PM, Howitt MR, Panikov N, Michaud M, Gallini CA, Bohlooly YM, et al. The microbial metabolites, short-chain fatty acids, regulate colonic Treg cell homeostasis. Science (2013) 341:569-73. doi:10.1126/science.1241165

87. Arpaia N, Campbell C, Fan X, Dikiy S, van der Veeken J, deRoos P, et al. Metabolites produced by commensal bacteria promote peripheral regulatory T-cell generation. Nature (2013) 504:451-5. doi:10.1038/nature12726

88. Furusawa Y, Obata Y, Fukuda S, Endo TA, Nakato G, Takahashi D, et al. Commensal microbe-derived butyrate induces the differentiation of colonic regulatory T cells. Nature (2013) 504:446-50. doi:10.1038/nature12721

89. Fischbach MA, Sonnenburg JL. Eating for two: how metabolism establishes interspecies interactions in the gut. Cell Host Microbe (2011) 10:336-47. doi:10.1016/j.chom.2011.10.002

90. Kim SV, Xiang WV, Kwak C, Yang Y, Lin XW, Ota M, et al. GPR15-mediated homing controls immune homeostasis in the large intestine mucosa. Science (2013) 340:1456-9. doi:10.1126/science.1237013

91. Chang PV, Hao L, Offermanns S, Medzhitov R. The microbial metabolite butyrate regulates intestinal macrophage function via histone deacetylase inhibition. Proc Natl Acad Sci U S A (2014) 111:2247-52. doi:10.1073/ pnas.1322269111

92. Singh N, Gurav A, Sivaprakasam S, Brady E, Padia R, Shi H, et al. Activation of Gpr109a, receptor for niacin and the commensal metabolite butyrate, suppresses colonic inflammation and carcinogenesis. Immunity (2014) 40:128-39. doi:10.1016/j.immuni.2013.12.007

93. Park J, Kim M, Kang SG, Jannasch AH, Cooper B, Patterson J, et al. Shortchain fatty acids induce both effector and regulatory $\mathrm{T}$ cells by suppression of histone deacetylases and regulation of the mTOR-S6K pathway. Mucosal Immunol (2015) 8:80-93. doi:10.1038/mi.2014.44

94. Garidou L, Pomie C, Klopp P, Waget A, Charpentier J, Aloulou M, et al. The gut microbiota regulates intestinal CD4 $\mathrm{T}$ cells expressing RORgammat and controls metabolic disease. Cell Metab (2015) 22:100-12. doi:10.1016/j. cmet.2015.06.001

95. Frank DN, St Amand AL, Feldman RA, Boedeker EC, Harpaz N, Pace NR. Molecular-phylogenetic characterization of microbial community imbalances in human inflammatory bowel diseases. Proc Natl Acad Sci U S A (2007) 104:13780-5. doi:10.1073/pnas.0706625104

96. Petersen C, Round JL. Defining dysbiosis and its influence on host immunity and disease. Cell Microbiol (2014) 16:1024-33. doi:10.1111/cmi.12308

97. Garrett WS, Lord GM, Punit S, Lugo-Villarino G, Mazmanian SK, Ito S, et al. Communicable ulcerative colitis induced by T-bet deficiency in the innate immune system. Cell (2007) 131:33-45. doi:10.1016/j.cell.2007.08.017

98. Garrett WS, Gallini CA, Yatsunenko T, Michaud M, DuBois A, Delaney ML, et al. Enterobacteriaceae act in concert with the gut microbiota to induce spontaneous and maternally transmitted colitis. Cell Host Microbe (2010) 8:292-300. doi:10.1016/j.chom.2010.08.004

99. Ott SJ, Musfeldt M, Wenderoth DF, Hampe J, Brant O, Folsch UR, et al. Reduction in diversity of the colonic mucosa associated bacterial microflora in patients with active inflammatory bowel disease. Gut (2004) 53:685-93. doi:10.1136/gut.2003.025403

Conflict of Interest Statement: The authors declare that the research was conducted in the absence of any commercial or financial relationships that could be construed as a potential conflict of interest.

Copyright $\odot 2015$ Omenetti and Pizarro. This is an open-access article distributed under the terms of the Creative Commons Attribution License (CC BY). The use, distribution or reproduction in other forums is permitted, provided the original author(s) or licensor are credited and that the original publication in this journal is cited, in accordance with accepted academic practice. No use, distribution or reproduction is permitted which does not comply with these terms. 